\title{
Comparative Investigations on Mahua Biodiesel-Diesel -Alcohol Low Percentage Blends with a VCR Diesel Engine
}

\author{
Nikhil D Chavan ${ }^{l}$, Amar P. Pandhare ${ }^{{ }^{*}}$ \\ ${ }^{1}$ Sinhgad College of Engineering, Pune 411041, Maharashtra, India
}

\begin{abstract}
In this analysis mahua oil biodiesel isselected as one of the best alternative fuel to diesel.Transesterficiation processisusedforbiodieselproduction.Serious concern on the emissions, in particularthe nitrogen oxides (NOx), PM (particulate matters) and carbondioxide $\left(\mathrm{CO}_{2}\right)$ led to think about additives to improve the overall performance. In this investigation additives are used to improve the performance, combustion and emission characteristics of Mahua biodiesel (B) and Diesel (D) blends. B20 blend is used as basic blend to compare the performance.Ethanol (E) and Propanol (P) used as additives indiesel-biodiesel blend with $5 \%, 10 \%$ and $15 \%$ and tested in VCR diesel engine. Ethanol shown better performance in particular as compare to Propanol. The reduction of $\mathrm{NOx}, \mathrm{CO}, \mathrm{CO}_{2}, \mathrm{HC}$ emission in diesel engine and also increase performance in addition of $10 \%$ ethanol. From this conclude the result ethanol is alternative to improve efficiency of diesel engine by using the blended biodiesel.
\end{abstract}

\section{Introduction}

The diesel fuel is commercial and transportation fuel. The rapid increment in the demand of fossil fuel such as a diesel has a great impact on economy of countries. The transportation sector is identified as major polluting sector. The crude oil prices are fluctuating in the global market. Biodiesel has a capacity to cut down the lump sum of expenditure on fuel. Biodiesel is important alternative to fossil fuels. Different types of biodiesel are largely studied in the past.Different alcohols in different percentage in biodiesel can change the emissions of engine significantly. Mahua oil biodiesel is ecofriendly better performing biodiesel.Biggest problems with the use of biodiesel are decrement in performance, Increase in the emissions and incomplete combustion.Additives are added to increase the performance of biodiesel in diesel engine. These additives are environment friendly and useful for the growth of farmers. Second generation ethanol and propanol are used as additives.

\section{Literature Review}

Additives such as ethanol and 1- propanol added into diesel blends. By adding them decrease in NOx and soot emission is found. At the same time $\mathrm{CO}$ emissions are increased[1].Alcohols such as methanol, ethanol, propanol, butanol and all having 5\% oxygen content are tested withwaste cooking oil diesel blends. It leads to reduction in emission of $\mathrm{HC}, \mathrm{NOx}, \mathrm{CO}, \mathrm{CO}_{2}[2]$. By using additives increase in oxidation stability and $4-5{ }^{\circ} \mathrm{C}$ change in cold flow properties achieved[3].Additives used in diesel-biodiesel blends are Propanol, n-butanol and 1-pentanol.Higher brake specific fuel consumption of D40B40Pro20 than ternary blends of D40B40nB20 and D40B40Pn20 at all engine loads[4]. D40B40Pro20, D40B40nB20 and D40B40Pn20 have the exhaust gas temperatures higher than that of the diesel-biodiesel blend[4]. Different oxygenates are considered for study. By adding 2-propanol in pseudo binary and ternary biodiesel density is measured at different temperatures. Excess molar value shows positive and negative effects on Performance. In this investigation Methanol (M)and Ethanol (E) used as additives. Reduction in emissions of $\mathrm{NOx}, \mathrm{CO}, \mathrm{CO}_{2} \mathrm{HC}$ takes place on addition of methanol in $10 \%$ and $15 \%[6]$.Biodiesel $(20 \%)$ added with $5 \%$ and $10 \%$ additives shows better performance in emission reduction. Fuel properties are found to be similar to conventional fuel. [7,8].NOx and PM emission are reduced. Operating conditions and biofuel concentration are important parameters in reducing emissions.[9].B20D80 blend shows better performance than other blends[10,11].Mahua oil biodiesel blended with octanol reduces emissions by significant amount significant results are found[12,13].diesel-biodieselethanol and bioethanol ternary blends are tested ternary blends shows better reduction in particulate matter other parameters are nearly same as like diesel[14,15].Mahua oil biodiesel shows better performance below $25 \%$ diesel blends. Less brake specific fuel consumption than the diesel. It has been proved by the results [16]. At the end Mahua oil biodiesel $20 \%$ blend is significant and less 
studied. Hence mahua oil biodiesel is selected for study to improve the performance of engine by using additives. Propanol and ethanol in low percentage are selected as additives.

\section{Material and method}

The Mahua oil feedstock is collected from Indian biodiesel corporation Baramati. Mahua oil initially with free fatty acids having density $910 \mathrm{gm} / \mathrm{cc}$ which are need to be removed.This feed stock is then undergoes esterification and transesterification process.Under esreification $\quad 0.4 \% \quad \mathrm{H} 2 \mathrm{SO} 4$ ACID catalyst by volume and $10 \%$ methanol as a solvent were added. Mixture then heated at 55-60 $0 \mathrm{C}$ and agitated at $550-600 \mathrm{rpm}$ for 30 minutes. At the end of esterification fatty acid count reduced to the $5-6 \mathrm{mg}$ from $17-18 \mathrm{mg}$ of $\mathrm{KOH}$. Density and viscosity of mahua oil then reduced by significant amount.Under transesterification esterified mahua oil mixed with $0.4 \% \mathrm{NaOH}$ AND $10 \%$ methanol and agitated at $550 \mathrm{rpm}$ at $600 \mathrm{C}$ for 75 minutes. Setteling of mixture for 8 to $10 \mathrm{hrs}$ resulted into $20 \%$ glycerol and $80 \%$ biodiesel. After purification and demoisturization at 110 0C for 20 minutes pure mahua oil biodiesel B100 obtained. Ethanol (E)and propanol(P)were added in $5 \%, 10 \%, 15 \%$ in B20 biodiesel blend. Diesel with $20 \%$ Mahua oil biodiesel used as base fuel with best performance. Different blends to be tested of list is given in Table 1.

Table 1. List of blends to be tested

\begin{tabular}{|c|c|c|c|c|}
\hline Blends & Diesel & Biodiesel & Propanol & Ethanol \\
\hline Diesel & $100 \%$ & - & - & - \\
\hline D80B20 & $80 \%$ & $20 \%$ & - & - \\
\hline D75B20E5 & $75 \%$ & $20 \%$ & - & $5 \%$ \\
\hline D70B20E10 & $70 \%$ & $20 \%$ & - & $10 \%$ \\
\hline D65B20E15 & $65 \%$ & $20 \%$ & - & $15 \%$ \\
\hline D75B20P5 & $75 \%$ & $20 \%$ & $5 \%$ & - \\
\hline D70B20P10 & $70 \%$ & $20 \%$ & $10 \%$ & - \\
\hline D65B20P15 & $65 \%$ & $20 \%$ & $15 \%$ & - \\
\hline
\end{tabular}

\section{Experimental setup and methodology}

The experimental setup consists of Kirloskar Computerized VCR engine of specification and details are given in Table 2 and Figure 1. Eddy current dynamometer is used to change the load from 0 to 16 . Compression ratio kept constant at 18. Engine and dynamometer are water cooled there flow rate is measured by rotameter and calorimeter. Piezo sensor, load cell and temperature sensors are used for performance measurement. Exhaust gas analyzer is connected to measure emissions ofNOx, $\mathrm{CO}, \mathrm{CO}_{2}, \mathrm{HC}$. Data acquisition is done by computer connected to the system.

The Diesel and blends D80B20, D75B20E5, D70B20E10 D65B20E15. D75B20P5, D70B20P10, D65B20P15 are tested respectively. During testing readings are taken when engine became totally steady. Loads are varied from 0 to 16 . While compression ratio kept constant. Computerized system generated results for various blends.

Table 2. Diesel engine specification and details

\begin{tabular}{|c|c|}
\hline Engine specification & Details \\
\hline Type & 1 cylinder 4 stroke \\
\hline Bore dia x stroke length & $87.5 \times 110 \mathrm{~mm}$ \\
\hline Cubic capacity & $661 \mathrm{cc}$ \\
\hline Compression ratio & 17.5 \\
\hline Piezo sensor Range & 5000 PSI,with low noise cable \\
\hline Maximum speed & $2000 \mathrm{rpm}$ \\
\hline Rotameter & $40-400 \mathrm{LPH}$ \\
\hline Connecting rod length & $234 \mathrm{~mm}$ \\
\hline Over dimensions & W2000 x D2500 x H 1500 mm \\
\hline Data acquisition device & Ni USB-5210, 16 bit ,250KS/s \\
\hline
\end{tabular}

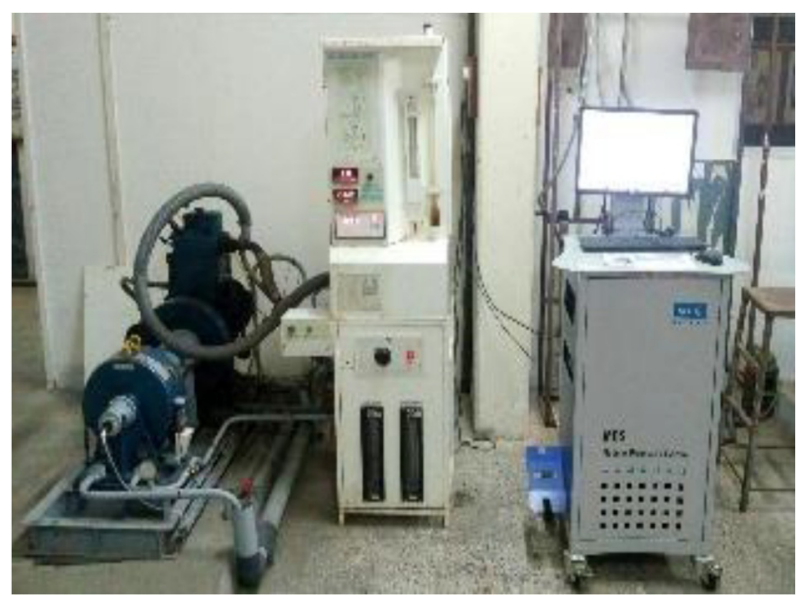

Fig. 1. Computerized VCR engine setup 


\section{Result and discussion}

\subsection{Performance}

\subsubsection{Brake power}

Fig.2. Shows graph of Break power with Load. At low load condition nearly all blends shows same break power variation. As we know that the engine efficiency is depends upon the brake power and it is directly proportional to the brake power. From the graph we can concluded that the by using blends we can slight increase the efficiency of the engine. The power output is $2 \%$ increases for ethanol concentration blend and maximum for D70B20E10 and D65B20E15 Due to the complete combustion occur in Diesel engine.

\subsubsection{Brake thermal efficiency}

Fig.3. Shows graph of Break thermal efficiency with Load. At low load condition nearly all blends shows same break power variation. At higher load little change in result takes place.Brake thermal efficiency increases with increase in BMEP up to 2.92 bars beyond that small increases or decrease for various blends This result is beacase of additional lubricity and oxygen content in oxygenates additives, which results into the reduction in heat loss and active combustion process.Average 2\% increment for D70 B20E10 as compare to diesel is seen as the load increases.D70B20E10 and D65B20E15 are coming out as best out of all blends as they are showing nearly $2 \%$ increment in the brake thermal efficiency.

\subsubsection{Indicated thermal efficiency}

Fig.4. Shows graph of Indicated thermal efficiencywith Load.The indicated thermal efficiency increases with addition of oxygenates both ethanol and propanol than pure diesel.The ethanol concentration blend is effective than the propanol concentration blend due to maximum oxygen content in ethanol concentration blend.Total increment in indicated thermal efficiency is about $3 \%$ for various loads.it is highest for the blend D70B20E10 and blend D65 B20E15.

\subsubsection{Brake specific fuel consumption}

Fig.5. shows graph of Specific fuel consumptionvs load condition.It is about $5 \%$ for various loads.Brake specific fuel consumption decreases with increase in load of the engine.The brake specific fuel consumption is lower for ethanol concentration blend due to lower viscosity than proanol, Hence the ethanol concentration blend consume less fuel than ethanol concentration blends. Brake specific fuel consumption is lower for the blend D70B20E10 AND D75B20E5. D70B20E10 shows less fuel consumption for all loads specially at higher loads.The Difference in specific fuel consumption is nearly about $1-2 \%$.

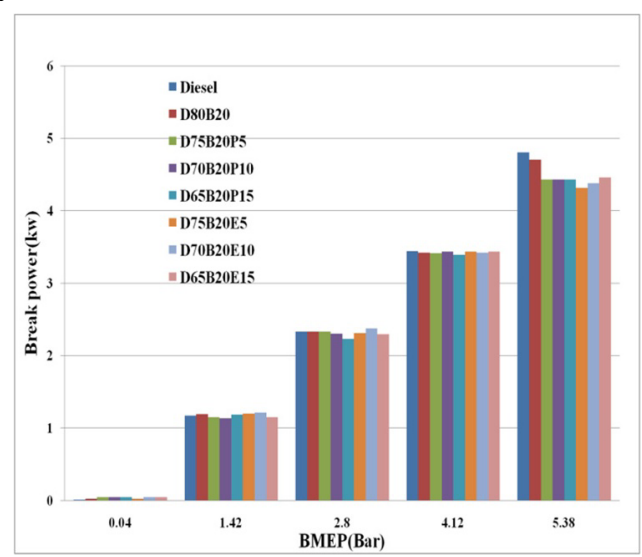

Fig. 2. Variation of Brake power with BMEP

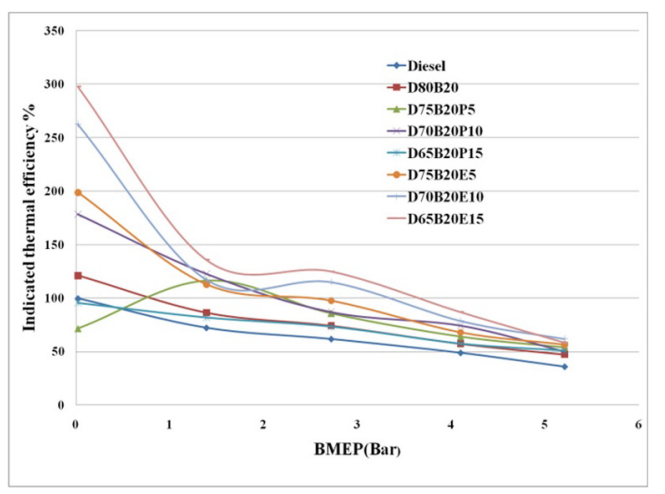

Fig. 3. Variation of brake thermal efficiency with BMEP

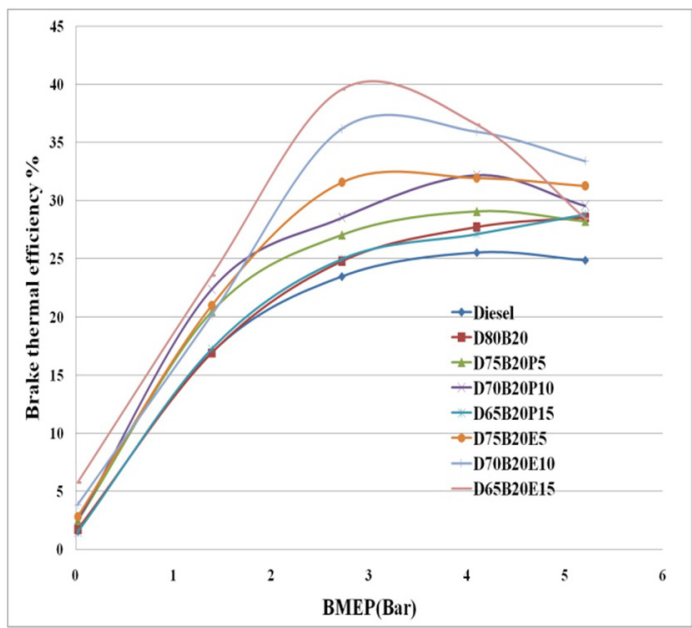

Fig. 4. Variation of indicated thermal efficiency with BMEP 


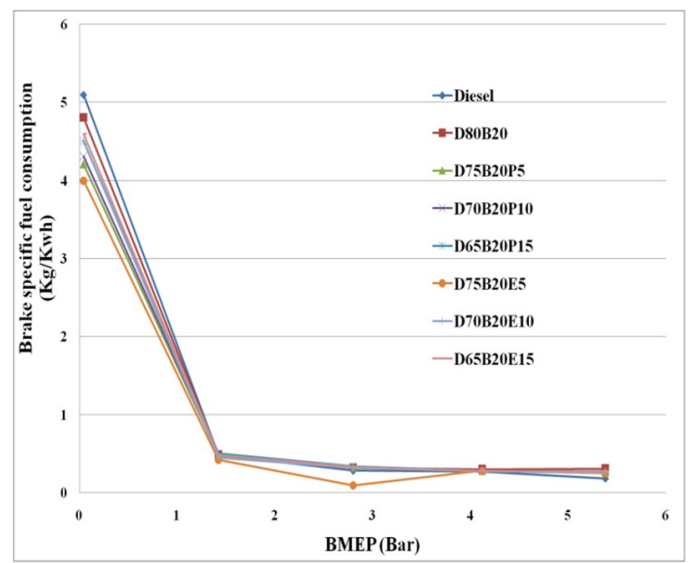

Fig. 5. Variation of Brake Specific fuel consumption with BMEP

\subsection{Emmisions}

Gas analyzer gives the results of emissions of $\mathrm{CO}$, $\mathrm{CO}_{2}, \mathrm{HC}$ and NOx are plotted on the graph.

\subsubsection{Carbon monoxide (CO) emission}

Fig.6. shows graph of carbon monoxide vs. changing load condition. CO is prodiced due to the incomplete combustion, which is formed due to scarcity of air or due to low gas temperature. $\mathrm{CO}$ emission decreases in addition of oxygenates in diesel.At higher load, the combustion of blends is almost complete due to the presence of oxygen which reduces the incomplete combustion of fuel in the region,results into to lesser $\mathrm{CO}$ emission. By more oxidation of $\mathrm{CO}$, smallest possible emission of D70B20E10 is observed at higher loading condition. Average 3\% decrement in $\mathrm{CO}$ emission is found for D70B20E10 which is highest as compare to other blends.

\subsubsection{Carbon dioxide $\left(\mathrm{CO}_{2}\right)$ emission}

Fig.7. shows graph of carbon dioxide vs. changing load condition.Fuel blend with ethanol and propanol has less $\mathrm{CO}_{2}$ emission as compare to diesel fuel.It is obsereved that the emission of $\mathrm{CO}_{2}$ increases with respective increase in load of the engine. Increasing percentage of ethanol in blend, decrease in $\mathrm{CO}_{2}$ emission is observed because of higher oxygen content and higher carbon in mahua biodiesel.Decrement of $\mathrm{CO}_{2}$ emission is $3 \%$ for all load conditions for the blend D70B20E10.

\subsubsection{Hydrocarbon (HC) emission}

Fig.8. shows graph of Hydrocarbon vs. changing load condition.Diesel and D75B20P5 have minimum HC emission at low load conditions. At higher loads D750B20P5 and ethanol blends have low HC emission.Overall less emission of $\mathrm{HC}$ is shown by D75B20P5 and D70B20E10. Reduction in emission of
$\mathrm{D} 70 \mathrm{~B} 20 \mathrm{E} 10$ is $3 \%$ as compare to $\mathrm{B} 20 \mathrm{D} 80 . \mathrm{HC}$ emission increases with addition of oxygenates than diesel at various loading condition. The result revealed that the $\mathrm{HC}$ emission for propanol concentration blends are less than ethanol concentration blends.HC emissions are found lowest for diesel due to less carbon and oxygen percentage as compared to various blends. The blends D70B20E10 and other shows contradictory results as compare to diesel.

\subsubsection{Nitrous oxide (NOx) emission}

Fig.9. shows graph of Nitrogen oxides vs. changing load condition.NOx emission decrease with increasing percentage of ethanol in the blend, this is due to the characteristic that lower heating value and latent heat of vaporization of ethanol as there is lesser peak temperature in the cylinder. In addition, this is due to the percentage of nitrogen in chemical composition of biodiesel and alcohol is less as compare to diesel. The NOx emission is decreases due to oxygenates added in biodiesel and diesel blend. The blend D70B20E10 and D65B20P15 shows minimum NOX emission as compare to other blends. It is nearly $5 \%$ decrement in NOX emission.

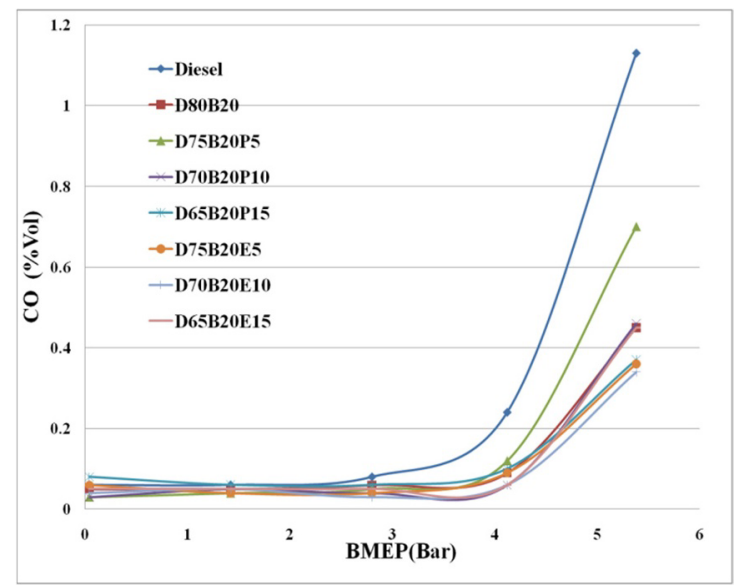

Fig. 6. Variation of CO with BMEP

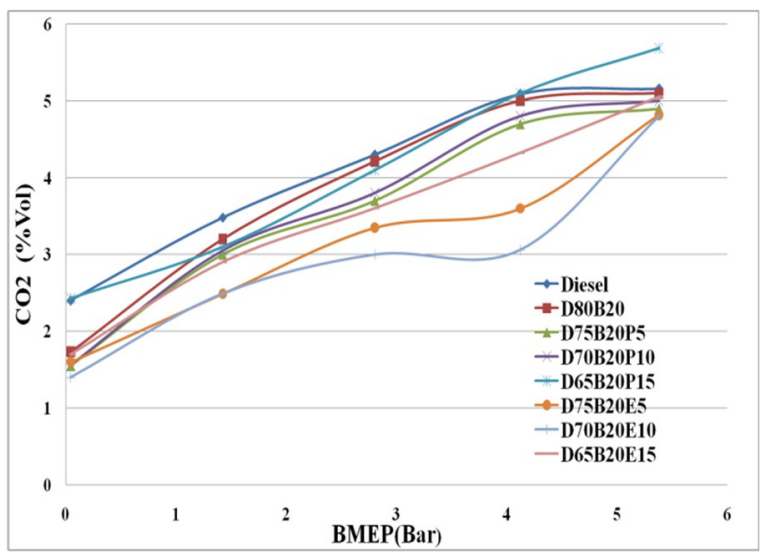

Fig. 7. Variation of $\mathrm{CO} 2$ with $\mathrm{BMEP}$ 


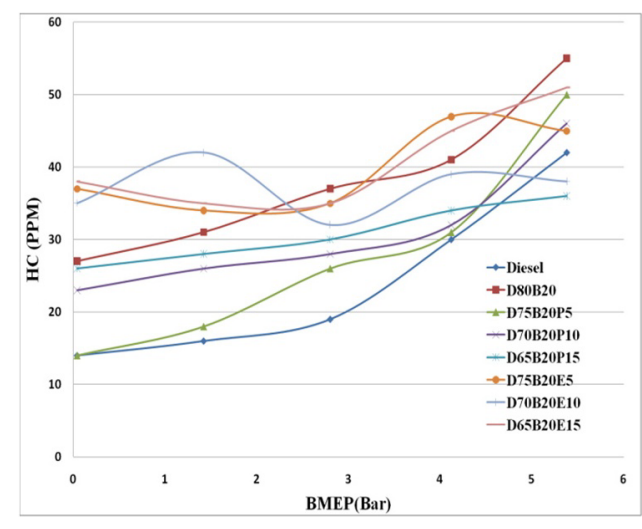

Fig. 8. Variation of $\mathrm{HC}$ with BMEP

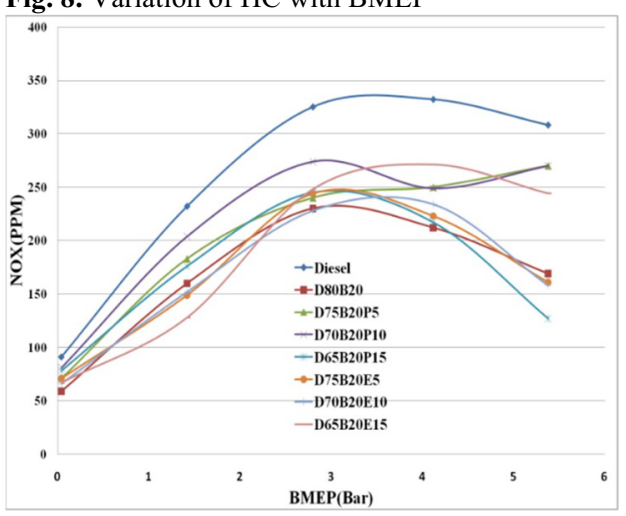

Fig. 9. Variation of NOX with BMEP

\section{Conclusions}

The experimental investigation concludes as given below

1 In performance the brake thermal efficiency for additives as a oxigenates is increased as compared to diesel. It is found maximum for the ethanol oxygenate blend (D70B20E10).

2 The brake specific fuel consumption is comparatively less as that of diesel fuel for D70B20E10 blend. It is $1-2 \%$ less for D70B20E10 blend.

3 The emission of $\mathrm{CO}$ is reduced by $2 \%$ on addition of ethanol in diesel and biodiesel. It is lowest for D70B20E10 blend.

4 The emission of NOx is reduced by $5 \%$ on addition of ethanol in diesel and biodiesel. It is lowest for D70B20E10 blend.

5 The emission of $\mathrm{HC}$ increases than diesel for both oxygenates and maximum for ethanol concentration blends.

6 From the experimental investigation, it can be concluded ethanol is found best oxygenate additives than that of propanol.

7 The effective blend found amongst the tested blend is D70B20E10.

\section{References}

S.Pinzi, JA.Soriano, 9th Int. Conf. on Applied Energy, ICAE2017, 142, 849, (2017).

M. A.Ghadikolaei, C.S.Cheung, Ka-Fu.Yung, Energy. 164, (2018).

I. Lawana,, W. Zhoua, Z. N. Garbaa, M. Zhanga,Z. Yuana, L.Chena, Ren. and Sustainable Energy Rev. 102, 83, (2019).

A. Atmanli , Fuel 176, 209, (2016).

A. Nayse, K. Sorate, Int. Engg. Res. Journal, Special Edition, (2017).

M. Yasin,R Mamat, A. Yusop, A. Aziz and G. Najafi,, Energy Procedia, 75, 10, (2015).

1. H Li , S. Xia , H. Luo , P. Ma,. Fuel, 173, 52, (2016).

M. Mofijur, M.G. Rasul, J. Hyde, Procedia Engineering, 105, 658, (2015).

M. Parida, H. Joardar, A.. Rout, I. Routaray, B. Mishra, App. Thermal Engg. (2018),

S Rajkumar, J Thangarajab, Fuel, 240, 101, (2019).

A Mahalingam , Y. Devarajan ,S. Radhakrishnan , S.Vellaiyan, B. Nagappan, Alexandria Engg. Jou. (2017)

2. M. Yasin , T Yusaf, R. Mamat, A. Fitri Yusop, Applied Energy 114, 865, (2014).

R. Sakthivela, K. Rameshb, R. Purnachandrana,

P. Shameera, Ren. and Sustainable Ene. Reviews 82, 2970, (2018)

S. Shahir,H. Masjuki, M. Kalam, A.Imran, A.Ashraful, Renewable and Sustainable Energy Reviews 48, 62, (2015)

S.nandi, American Journal of Engineering Research 2, 22.

AP.Pandhare, Journal of Renewable Energy, 11, (2013) 